\title{
Growth of $\mathrm{SnO}_{2}$ Nanoflowers on N-doped Carbon Nanofibers as Anode for Li- and Na-ion Batteries
}

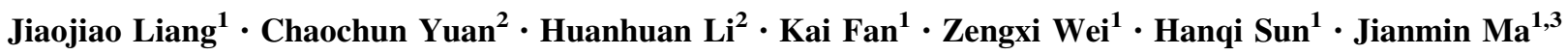

Received: 6 September 2017 / Accepted: 7 November 2017/Published online: 8 December 2017

(C) The Author(s) 2017. This article is an open access publication

\section{Highlights}

- A hybrid structure of $\mathrm{SnO}_{2}$ nanoflowers grown on N-doped carbon nanofibers $\left(\mathrm{NC} @ \mathrm{SnO}_{2}\right)$ was successfully constructed.

- $\mathrm{N}$-doped carbon nanofiber accelerates the migration of $\mathrm{Li}^{+} / \mathrm{Na}^{+}$ions and guides the growth of the $\mathrm{SnO}_{2}$ nanoflowers.

- $\mathrm{NC} @ \mathrm{SnO}_{2}$ electrode reveals excellent energy storage performance for $\mathrm{Li}$ - and $\mathrm{Na}$-ion batteries.

\begin{abstract}
It is urgent to solve the problems of the dramatic volume expansion and pulverization of $\mathrm{SnO}_{2}$ anodes during cycling process in battery systems. To address this issue, we design a hybrid structure of $\mathrm{N}$-doped carbon fibers@ $\mathrm{SnO}_{2}$ nanoflowers $\left(\mathrm{NC} @ \mathrm{SnO}_{2}\right)$ to overcome it in this work. The hybrid $\mathrm{NC@} \mathrm{SnO}_{2}$ is synthesized through the hydrothermal growth of $\mathrm{SnO}_{2}$ nanoflowers on the surface of $\mathrm{N}$-doped carbon fibers obtained by electrospinning. The NC is introduced not only to provide a support framework in guiding the growth of the $\mathrm{SnO}_{2}$ nanoflowers and prevent the flower-like structures from agglomeration, but also serve as a conductive
\end{abstract}

Electronic supplementary material The online version of this article (https://doi.org/10.1007/s40820-017-0172-2) contains supplementary material, which is available to authorized users.

Jiaojiao Liang and Chaochun Yuan have contribution equal to this work.

Jianmin Ma

nanoelechem@hnu.edu.cn

1 School of Physics and Electronics, Hunan University, Changsha 410082, People's Republic of China

2 Automotive Engineering Research Institute, Jiangsu University, Zhenjiang 212013, People's Republic of China

3 Key Laboratory of Advanced Energy Materials Chemistry (Ministry of Education), Nankai University, Tianjin 300071, People's Republic of China
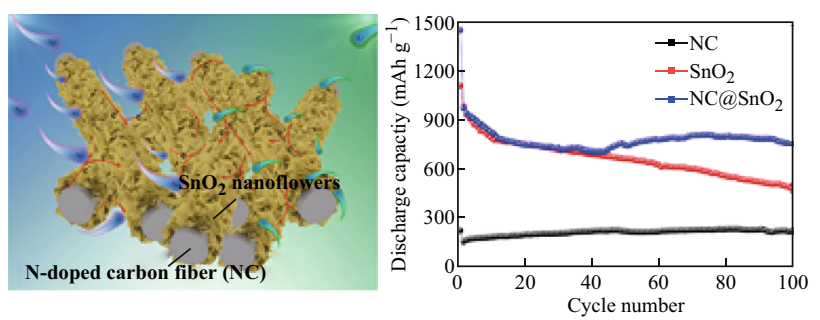

network to accelerate electronic transmission along one-dimensional structure effectively. When the hybrid NC@ $\mathrm{SnO}_{2}$ was served as anode, it exhibits a high discharge capacity of $750 \mathrm{mAh} \mathrm{g}^{-1}$ at $1 \mathrm{~A} \mathrm{~g}^{-1}$ after 100 cycles in Li-ion battery and $270 \mathrm{mAh} \mathrm{g}^{-1}$ at $100 \mathrm{~mA} \mathrm{~g}^{-1}$ for 100 cycles in Na-ion battery, respectively.

Keywords $\mathrm{SnO}_{2} \cdot$ Nanostructures $\cdot$ Anode $\cdot$ Li-ion battery $\cdot$ Na-ion battery

\section{Introduction}

With severe resource constraints and global environmental problems, it is necessary to develop highly efficient energy storage systems to reduce the use of fossil fuels [1-5]. Nowadays, lithium- and sodium-ion batteries (LIBs and 
SIBs) have attracted widespread attention all over the world [6-8]. LIBs have been extensively applied in portable electronic equipment and electric vehicles (EVs) and intelligent power grids because of their outstanding characteristics of high energy density, no memory effect, and small self-discharge [9, 10]. Recently, owing to the lack of lithium resources and the similar chemical property of $\mathrm{Na}^{+}$to $\mathrm{Li}^{+}$, SIBs have also received increasing attention [11, 12]. As one of the important parts for LIBs or SIBs, the high-performance electrode materials are urgently needed for nextgeneration battery systems.

As one of the typical transition-metal oxides (TMOs), tin dioxide $\left(\mathrm{SnO}_{2}\right)$ is widely concerned to be promising electrode materials owing to its non-toxicity, low cost, high theoretical capacity, and outstanding electrochemical performance [13-15]. Nevertheless, it is similar to the shortcomings of other oxide materials during cycling processes that $\mathrm{SnO}_{2}$ endures the dramatic volume change. This would lead to the capacity decay and poor cycling performance [16-18]. To improve the electrochemical performance of $\mathrm{SnO}_{2}$, nanostructured $\mathrm{SnO}_{2}$ is employed to reduce the volume variation of $\mathrm{SnO}_{2}$ during the charge/discharge process [19-21]. However, it is easily agglomerated for nanostructured $\mathrm{SnO}_{2}$ to reduce the specific surface area of the active materials, leading to the attenuation of energy storage. To overcome this problem, a great deal of $\mathrm{SnO}_{2} /$ carbon composites has been designed to maintain the structural stability of electrodes and improve the electrical conductivity of composites [22-24]. In addition, the N-doped carbon composite materials are considered to enhance the electrical conductivity and accelerate the reaction speed of the $\mathrm{SnO}_{2}$ composites, and increase defect sites for the efficient storage of lithium/sodium ions [25-27].

In this work, we synthesized a hybrid structure of $\mathrm{N}$-doped carbon fibers@ $\mathrm{SnO}_{2}$ nanoflowers $\left(\mathrm{NC} @ \mathrm{SnO}_{2}\right)$ by electrospinning/hydrothermal methods. When they are used as an anode material in LIBs and SIBs, the as-prepared $\mathrm{NC} @ \mathrm{SnO}_{2}$ hybrid material displayed excellent electrochemical properties. The high discharge capacity reached $750 \mathrm{mAh} \mathrm{g}^{-1}$ at a current density of $1 \mathrm{~A} \mathrm{~g}^{-1}$ after 100 cycles in LIBs. Meanwhile, a reversible discharge capacity of $270 \mathrm{mAh} \mathrm{g}^{-1}$ was achieved at a current density of $100 \mathrm{~mA} \mathrm{~g}^{-1}$ after 100 cycles in SIBs.

\section{Experimental Section}

\subsection{Synthesis of $\mathrm{SnO}_{2}$, N-doped Carbon, and $\mathrm{NC} @ \mathrm{SnO}_{2}$}

All chemical reagents were purchased and used without further treatment. The synthesis of $\mathrm{SnO}_{2}$ nanoflowers was carried out according to the previous literature [28]. The
N-doped carbon (NC) nanofibers were synthesized by electrospinning as follows: $0.6 \mathrm{~g}$ polyacrylonitrile (PAN, Sigma-Aldrich Co., Ltd. USA) was firstly added into 7 g N,N-dimethylformamide (DMF, Sinopharm Chemical Reagent Co., Ltd., China). Then, the above solution was poured into $10-\mathrm{mL}$ plastic syringe and followed by electrospinning. The $\mathrm{NC}$ nanofibers were finally obtained via annealing the precursor at $600{ }^{\circ} \mathrm{C}$ in Ar atmosphere. To synthesize $\mathrm{NC@SnO}$, $4 \mathrm{mmol}$ tin(II) chloride dihydrate $\left(\mathrm{SnCl}_{2} \cdot 2 \mathrm{H}_{2} \mathrm{O}\right.$, Xilong Chemical Co., Ltd., China) and $8 \mathrm{mmol}$ sodium citrate $\left(\mathrm{Na}_{3} \mathrm{C}_{6} \mathrm{H}_{5} \mathrm{O}_{72} \cdot \mathrm{H}_{2} \mathrm{O}\right.$, Tianjin Hengxing Chemical Reagent Manufacturing Co., Ltd., China) were firstly dissolved into the mixed solvent of $15 \mathrm{~mL}$ ethanol and $15 \mathrm{~mL}$ water. After stirring for $30 \mathrm{~min}$, $80 \mathrm{mg}$ NC nanofibers were introduced into the above blend solution. Subsequently, the mixture solution was put into a Teflon-lined stainless steel autoclave at $180{ }^{\circ} \mathrm{C}$ for $12 \mathrm{~h}$ after continuous ultrasound for $30 \mathrm{~min}$. The precursor samples were taken out the autoclave after the end of the reaction and ultrasonic cleaning with deionized water and ethanol. Finally, the $\mathrm{NC} @ \mathrm{SnO}_{2}$ samples were obtained with annealing at $500{ }^{\circ} \mathrm{C}$ for $3 \mathrm{~h}$ in $\mathrm{Ar}$ gas.

\subsection{Material Characterizations}

The X-ray diffraction (XRD) of the samples was conducted with a Shimadzu XRD-6000 instrument, and the morphologies and structural features of the samples were characterized by scanning electron microscopy (SEM, Hitachi S4800) and transmission electron microscopy (TEM; JEOL 2010 with an accelerating voltage of $200 \mathrm{kV}$ ). The thermogravimetric analysis (TGA) of the powder sample was surveyed with a WCT-1D instrument (BOIF, China) in air atmosphere from 30 to $800{ }^{\circ} \mathrm{C}$. Brunauer-Emmett-Teller (BET) of the sample was performed with the adsorption of $\mathrm{N}_{2}$ with a nova 2000 e volumetric adsorption analyzer (Kangta, USA), The element composition and chemical bonds of the sample were detected by X-ray photoelectron spectroscopy (XPS, Thermo Scientific Escalab 250Xi, USA). Raman spectra of the samples were conducted by utilizing micro-Raman spectrometer (LabRAM HR Evolution, HORIBA).

\subsection{Electrochemical Measurements}

The working electrodes of LIBs and SIBs were fabricated by using $80 \mathrm{wt} \%$ of active materials $\left(\mathrm{NC} @ \mathrm{SnO}_{2}, \mathrm{SnO}_{2}\right.$, and NC), $10 \mathrm{wt} \%$ of acetylene black, and $10 \mathrm{wt} \%$ of carboxymethylcellulose sodium (CMC). The mixture was uniformly distributed in the deionized water and ethanol and coated on the copper foil which dried at $60{ }^{\circ} \mathrm{C}$ in a vacuum drying oven for a day. CR2025-type coin halfbatteries of as-prepared electrodes were assembled in the 
glove box with water and oxygen content of less than $0.5 \mathrm{ppm}$. The microporous polypropylene (Celgard 2400) and glass microfiber filter membranes (Whatman, Grade GF/A) were utilized as a separator of LIBs and SIBs, respectively. And corresponding metal plates were used as the counter electrodes of batteries. The electrolyte of LIBs was composed of $1.0 \mathrm{M}$ of $\mathrm{LiPF}_{6}$ solution which mixed ethylene carbonate (EC) and dimethyl carbonate (DMC) with 1:1 in volume, and the electrolyte of SIBs was constituted by $1.0 \mathrm{M}$ of $\mathrm{NaClO}_{4}$ solution which mixed EC with DMC (1:1 in volume), accompanied with 5\% fluoroethylene carbonate (FEC) of additive agent. The electrochemical property and cyclic voltammetry measurement of LIBs and SIBs were performed with Neware Battery Testing System and CHI 660C Electrochemical Workstation, respectively.

\section{Results and Discussion}

The synthetic process of $\mathrm{NC} @ \mathrm{SnO}_{2}$ is schematically shown in Fig. 1. Firstly, NC nanofibers were synthesized by the electrospinning method using PAN as the precursor, followed by heat treatment. Subsequently, $\mathrm{SnO}_{2}$ nanoflowers were grown on the NC nanofibers by hydrothermal method. The morphology and structures of the samples were characterized by SEM and TEM, as displayed in Fig. 2. Figure $2 \mathrm{a}, \mathrm{b}$ displays that $\mathrm{SnO}_{2}$ sample is composed of agglomerated nanoflowers, which are assembled by

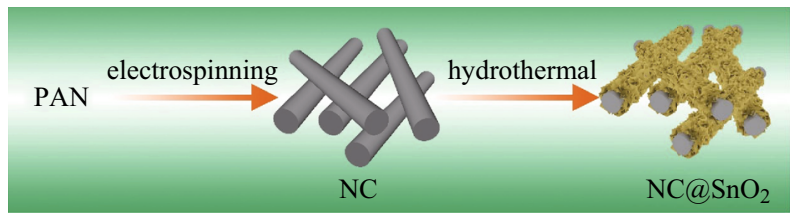

Fig. 1 Schematic diagram for synthetic process of $\mathrm{NC} @ \mathrm{SnO}_{2}$. (Color figure online)

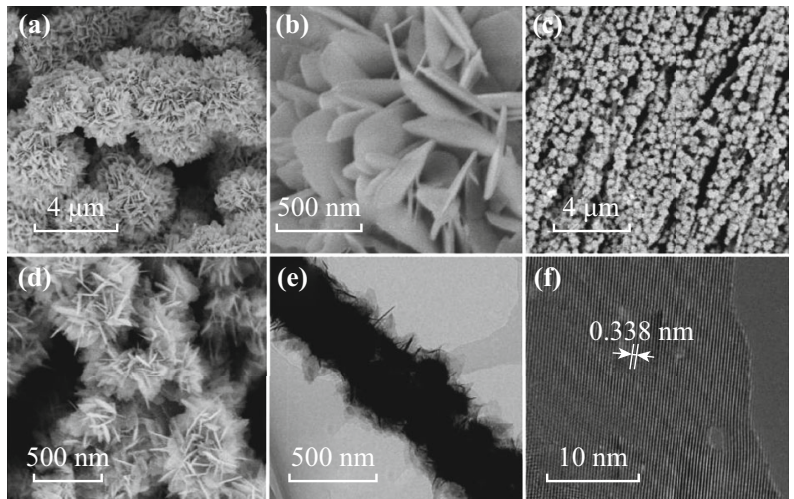

Fig. 2 a, b SEM images of $\mathrm{SnO}_{2}$. c, d SEM images and e, $\mathbf{f}$ TEM images of $\mathrm{NC} @ \mathrm{SnO}_{2}$ nanosheets. When the NC nanofibers (Fig. S1) are introduced and used as the core for the hybrid structure, the $\mathrm{SnO}_{2}$ nanoflowers could grow on the surface of NC nanofibers, as shown in SEM images (Fig. 2c, d). Compared to $\mathrm{SnO}_{2}$ nanoflowers, the $\mathrm{NC} @ \mathrm{SnO}_{2}$ composite materials are formed by thinner nanosheets and better dispersed. In addition, the TEM image (Fig. 2e) of $\mathrm{NC} @ \mathrm{SnO}_{2}$ further indicates that one fiber is completely covered with the thin nanosheets. The high-resolution TEM image (Fig. 2f) indicates that the $\mathrm{SnO}_{2}$ nanosheet is well crystalline and has a lattice plane (110) with a crystal lattice distance of $0.338 \mathrm{~nm}$.

The crystal structures of $\mathrm{NC} @ \mathrm{SnO}_{2}, \mathrm{SnO}_{2}$, and $\mathrm{NC}$ materials were analyzed by XRD. From Fig. 3, one can observe that the diffraction peaks of $\mathrm{NC} @ \mathrm{SnO}_{2}$ and $\mathrm{SnO}_{2}$ are well consistent with the standard card (JCPDS card No. 21-1250), and the $2 \theta$ values of main peaks centered at $26.58,33.88,37.95,51.75$, and 54.76 are corresponded to the lattice planes of tetragonal $\mathrm{SnO}_{2}$ (110), (101), (200), (211), and (220), respectively. The diffraction peaks of NC are in accordance with the standard card (JCPDS card No. $3-401$ ), and the $2 \theta$ values 26.60 and 54.79 are corresponded to the lattice planes of hexagonal carbon (006) and (0012), respectively. Nevertheless, the peak of carbon for the $\mathrm{NC} @ \mathrm{SnO}_{2}$ is not clearly observed. It is possible that the $\mathrm{NC}$ nanofibers were completely covered by the $\mathrm{SnO}_{2}$ nanoflowers, which make the carbon peaks disappear in $\mathrm{NC} @ \mathrm{SnO}_{2}$. The Raman spectrum of $\mathrm{NC} @ \mathrm{SnO}_{2}$ (Fig. S2) indicates that the two peaks at $\sim 1350$ and $1580 \mathrm{~cm}^{-1}$ are corresponded to the D peak of disorder carbon and the $G$ peak of graphitic carbon. The relative intensity $\left(I_{\mathrm{D}} /\right.$ $I_{\mathrm{G}} \approx 1.397>1$ ) indicates that there exist mass defects caused by the N-doping in $\mathrm{NC} @ \mathrm{SnO}_{2}$ [29-31]. Addition-

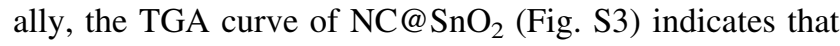
the lost weight of the sample appears in the range of $400-800{ }^{\circ} \mathrm{C}$ and the weight retention of $\mathrm{SnO}_{2}$ is confirmed to be about $67.81 \%$.

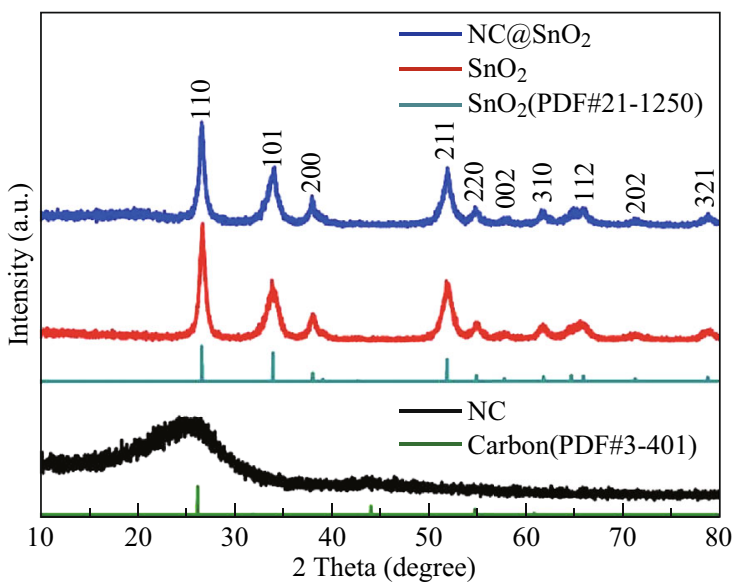

Fig. 3 XRD patterns of $\mathrm{NC} @ \mathrm{SnO}_{2}, \quad \mathrm{SnO}_{2}$, and NC. (Color figure online) 
The BET was utilized to confirm the surface information of the materials. Figure S4a, b shows the nitrogen adsorption-desorption isotherms of $\mathrm{NC} @ \mathrm{SnO}_{2}$ and $\mathrm{SnO}_{2}$ materials. The surface areas of $\mathrm{NC} @ \mathrm{SnO}_{2}$ and $\mathrm{SnO}_{2}$ are 45.59 and $37.01 \mathrm{~cm}^{3} \mathrm{~g}^{-1}$, respectively. Meanwhile, the pore-size distribution curves (Figs. S4c, d) indicate that the $\mathrm{NC} @ \mathrm{SnO}_{2}$ and $\mathrm{SnO}_{2}$ have the average pores of 3.74 and $2.56 \mathrm{~nm}$, respectively. The larger specific surface area and pore size of $\mathrm{NC} @ \mathrm{SnO}_{2}$ are beneficial to the storage and transport of lithium/sodium ions. Moreover, the chemical component and surface electronic states of the $\mathrm{NC} @ \mathrm{SnO}_{2}$ material were further surveyed by XPS, and all peaks of these elements $\mathrm{Sn}, \mathrm{O}, \mathrm{N}$, and $\mathrm{C}$ are observed as shown in Fig. S5 [32]. The high-resolution spectra of Sn 3d, O 1s, N $1 \mathrm{~s}$, and $\mathrm{C} 1 \mathrm{~s}$ were recorded as shown in Fig. 4. The peaks of the Sn 1s (Fig. 4a) could be resolved into 486.78 and $495.12 \mathrm{eV}$, which are assigned to the binding energies of $\mathrm{Sn} 3 \mathrm{~d}_{5 / 2}$ and $\mathrm{Sn} 3 \mathrm{~d}_{3 / 2}$ of $\mathrm{SnO}_{2}$ [33]. The peaks of the $\mathrm{O} 1 \mathrm{~s}$ (Fig. 4b) can be divided into two peaks of 530.61 and $531.36 \mathrm{eV}$ and corresponded to $\mathrm{Sn}-\mathrm{O}$ and $\mathrm{C}=\mathrm{O}$, respectively [34, 35]. The signal of $\mathrm{N} 1 \mathrm{~s}$ could be obviously divided into two peaks of 398.00 and $399.76 \mathrm{eV}$ (Fig. 4c), which well accorded with the binding energies of pyridinic $\mathrm{N}$ and pyrrolic $\mathrm{N}$ [36], it is verified the existence of nitrogen in $\mathrm{NC} @ \mathrm{SnO}_{2}$. Additionally, the peaks of the $\mathrm{C} 1 \mathrm{~s}$
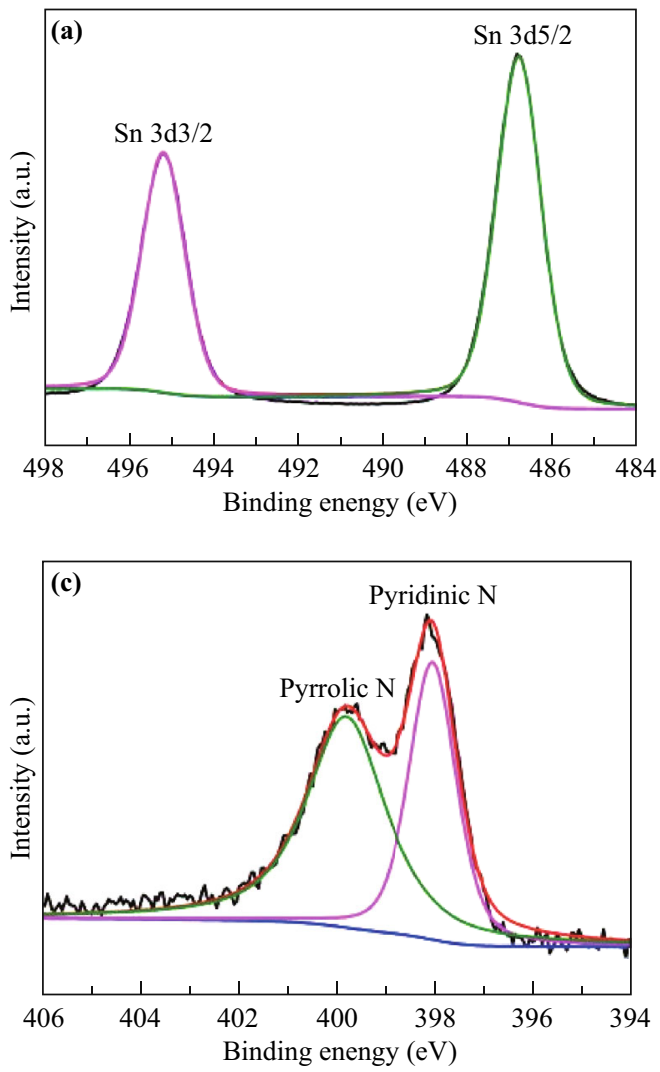

(Fig. 4d) could be resolved into three binding energies. The peak located at $285.89 \mathrm{eV}$ corresponding to $\mathrm{C}-\mathrm{N}$ bond can

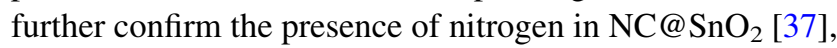
and the other peaks of 284.42 and $288.54 \mathrm{eV}$ are accorded with the binding energies of $\mathrm{C}-\mathrm{C}$ and $\mathrm{C}=\mathrm{O}$, respectively [38].

The $\mathrm{NC} @ \mathrm{SnO}_{2}$ was investigated as anode material for LIBs. $\mathrm{SnO}_{2}$ and $\mathrm{NC}$ nanofiber were also conducted for comparison. The CV curves of $\mathrm{NC} @ \mathrm{SnO}_{2}$ between 0.001 and $3.0 \mathrm{~V}$ vs $\mathrm{Li}^{+} / \mathrm{Li}$ at scan rate of $0.1 \mathrm{mV} \mathrm{s}^{-1}$ are shown in Fig. 5a, and it can be observed that there exists a subtle distinction in the first three cycles. The reduction peaks are found at the scope of $1.5-1.8$ and $0.5-1.0 \mathrm{~V}$ at the first curve. They are attributed to the conversion process from $\mathrm{SnO}_{2}$ to $\mathrm{Sn} \mathrm{(Eq.} \mathrm{1)} \mathrm{and} \mathrm{the} \mathrm{formation} \mathrm{of} \mathrm{SEI} \mathrm{films,}$ respectively [39, 40]. The peak below $0.5 \mathrm{~V}$ is associated with the lithiation $\left(\mathrm{Li}_{\mathrm{x}} \mathrm{Sn}\right)$ of $\mathrm{Sn}$ (Eq. 2) [41]. In the following two $\mathrm{CV}$ curves, the reduction peaks at about 1.2, 0.8 , and $0.3 \mathrm{~V}$ are associated with the reversible conversion reaction of $\mathrm{SnO}_{2}$ and alloy-dealloy reaction of $\mathrm{Sn}$ [42]. The oxidation peaks of about $0.8,1.2 \mathrm{~V}$ and the small oxidation peak of $2.1 \mathrm{~V}$ are derived from the delithiation reaction of $\mathrm{Li}_{\mathrm{x}} \mathrm{Sn}$ (Eq. 3) and reversible changing reaction of $\mathrm{Sn}$ between $\mathrm{SnO}$ and $\mathrm{SnO}_{2}$ (Eq. 4), respectively [42]. The $\mathrm{Li}^{+}$
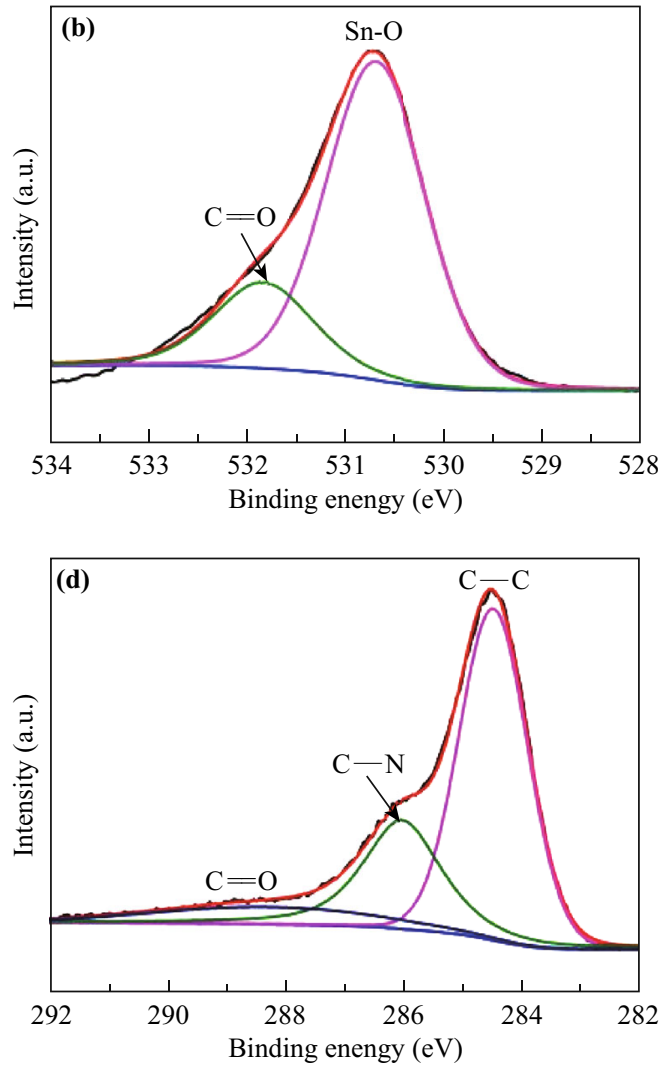

Fig. 4 XPS spectra of the $\mathrm{NC} @ \mathrm{SnO}_{2}$ : a Sn 3d, b O 1s, c N 1s, and d C 1s. (Color figure online) 

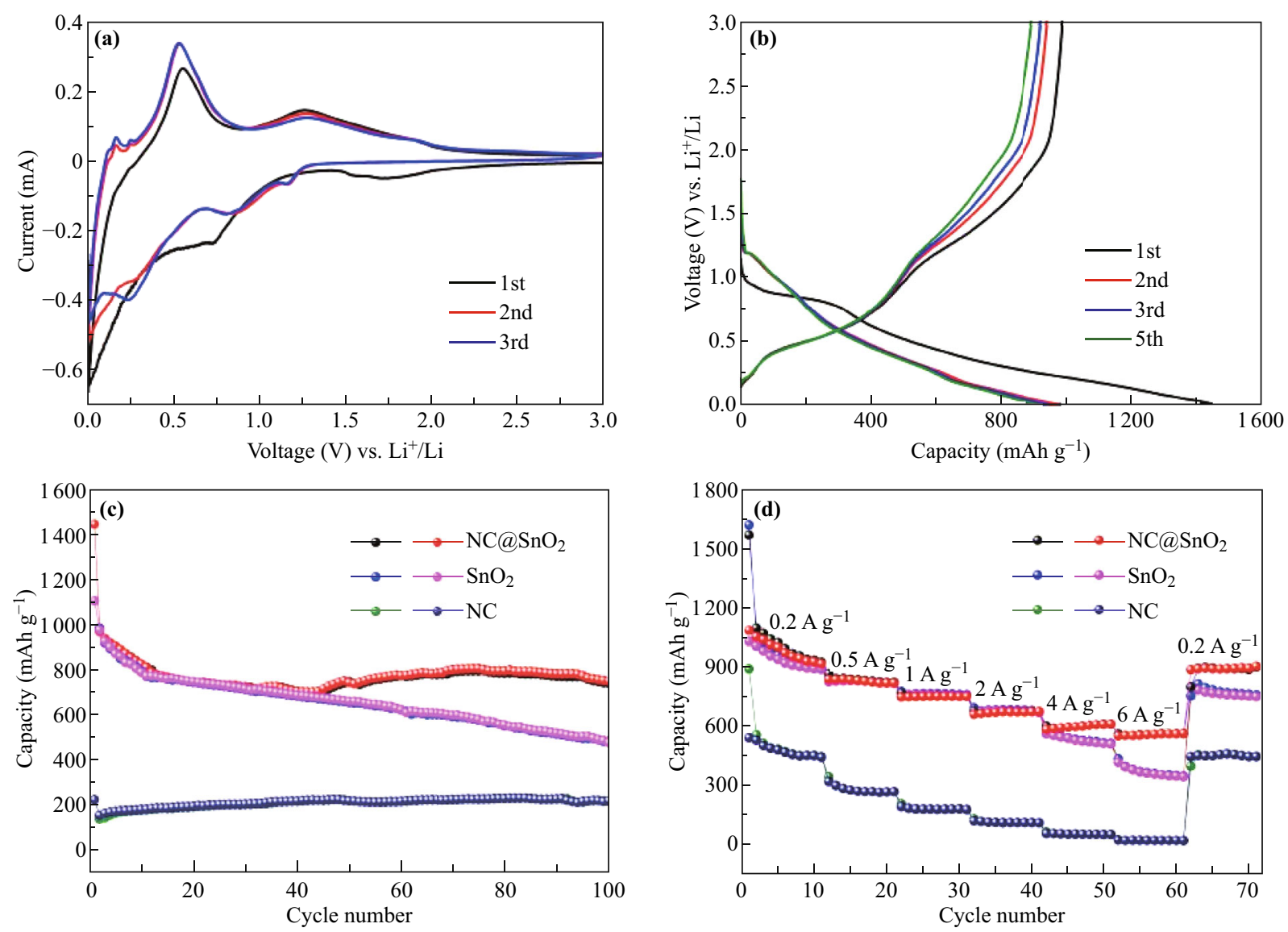

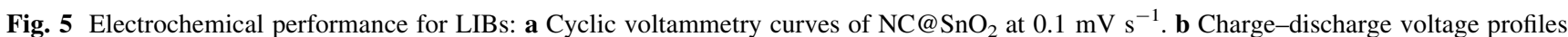
of $\mathrm{NC} @ \mathrm{SnO}_{2}$. c Cycling performances of $\mathrm{NC} @ \mathrm{SnO}_{2}, \mathrm{SnO}_{2}$, and $\mathrm{NC}$ at $1 \mathrm{~A} \mathrm{~g}^{-1}$. d Rate capabilities of $\mathrm{NC}_{0} @ \mathrm{SnO}_{2}, \mathrm{SnO}_{2}$, and $\mathrm{NC}$. (Color figure online)

de/intercalation of conversion process is described as follows,

$\mathrm{SnO}_{2}+4 \mathrm{Li}^{+}+4 \mathrm{e}^{-} \rightarrow \mathrm{Sn}+2 \mathrm{Li}_{2} \mathrm{O}$

$\mathrm{Sn}+\mathrm{xLi}^{+}+\mathrm{xe}^{-} \rightarrow \mathrm{Li}_{\mathrm{x}} \mathrm{Sn}(0<\mathrm{x}<4.4)$

$\mathrm{Li}_{\mathrm{x}} \mathrm{Sn} \rightarrow \mathrm{Sn}+\mathrm{xLi}^{+}+\mathrm{xe}^{-}(0<\mathrm{x}<4.4)$,

$\mathrm{Sn} / \mathrm{SnO}+\mathrm{Li}_{2} \mathrm{O} \rightarrow \mathrm{SnO} / \mathrm{SnO}_{2}+2 \mathrm{Li}^{+}+2 \mathrm{e}^{-}$.

The charge/discharge profiles of $\mathrm{NC} @ \mathrm{SnO}_{2}$ at the 1st, 2nd, 3rd, and 5th cycle were displayed at in Fig. 5b. The voltage platforms of charge-discharge can be observed to be consistent with the oxidation-reduction peaks of above $\mathrm{CV}$ curves. The initial discharge-charge capacities of $\mathrm{NC} @ \mathrm{SnO}_{2}$ are 1463.6 and $1009.8 \mathrm{mAh} \mathrm{g}^{-1}$, respectively. And the low initial coulombic efficiency of $67.0 \%$ may be associated with the formation of SEI film and the irreversible reactions of $\mathrm{SnO}_{2}$ material in the first cycle $[32,43]$. The cycling performance of $\mathrm{NC} @ \mathrm{SnO}_{2}, \mathrm{SnO}_{2}$, and $\mathrm{NC}$ is shown in Fig. 5c. The discharge capacity of $\mathrm{NC} @ \mathrm{SnO}_{2}$ is about $750 \mathrm{mAh} \mathrm{g}^{-1}$ at $1 \mathrm{~A} \mathrm{~g}^{-1}$ after 100 cycles, while the discharge capacities of $\mathrm{SnO}_{2}$ and $\mathrm{NC}$ only remain 480 and $220 \mathrm{mAh} \mathrm{g}^{-1}$, respectively. In Fig. 5d, one can see that the average capacities of $\mathrm{NC} @ \mathrm{SnO}_{2}$ are about $1100,850,763,684,615,568$, and $905 \mathrm{mAh} \mathrm{g}^{-1}$ at different current densities of $0.2,0.5,1,2,4,6$, and $0.2 \mathrm{~A} \mathrm{~g}^{-1}$, respectively. However, the average capacities of $\mathrm{SnO}_{2}$ are only about $966,842,765,685,525,370$, and $770 \mathrm{mAh} \mathrm{g}^{-1}$ at $0.2,0.5,1,2,4,6$, and $0.2 \mathrm{~A} \mathrm{~g}^{-1}$, respectively. And the $\mathrm{NC}$ electrode exhibits the capacities less than $550 \mathrm{mAh} \mathrm{g}^{-1}$ at various current densities.

The electrochemical property of $\mathrm{NC} @ \mathrm{SnO}_{2}$ was further investigated in SIBs. Figure 6a displays the $\mathrm{CV}$ curves of

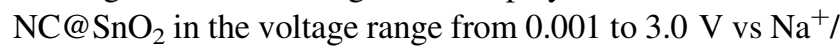
$\mathrm{Na}$ at scan rate of $0.1 \mathrm{mV} \mathrm{s}^{-1}$. The obvious slope of $0.5-1.0 \mathrm{~V}$ is ascribed to the generation of the SEI film and the irreversible reactions between $\mathrm{SnO}_{2}$ with sodium ions to generate $\mathrm{Na}_{\mathrm{x}} \mathrm{Sn}$ alloys in the first cycle [22]. In the initial three cycles, the two reduction peaks at about 1.0 and $0.3 \mathrm{~V}$ correspond to the insertion of sodium ions with the formation of $\mathrm{Sn}$ and $\mathrm{Na}_{\mathrm{x}} \mathrm{Sn}$, respectively. And the oxidation peak at $1.25 \mathrm{~V}$ corresponds to the de-intercalation of sodium ions $[44,45]$. The reversible reaction of $\mathrm{SnO}_{2}$ with sodium ions to the production of $\mathrm{Na}_{2} \mathrm{O}$ and $\mathrm{Na}_{\mathrm{x}} \mathrm{Sn}$ in the charge-discharge process can be represented as follows [44], 

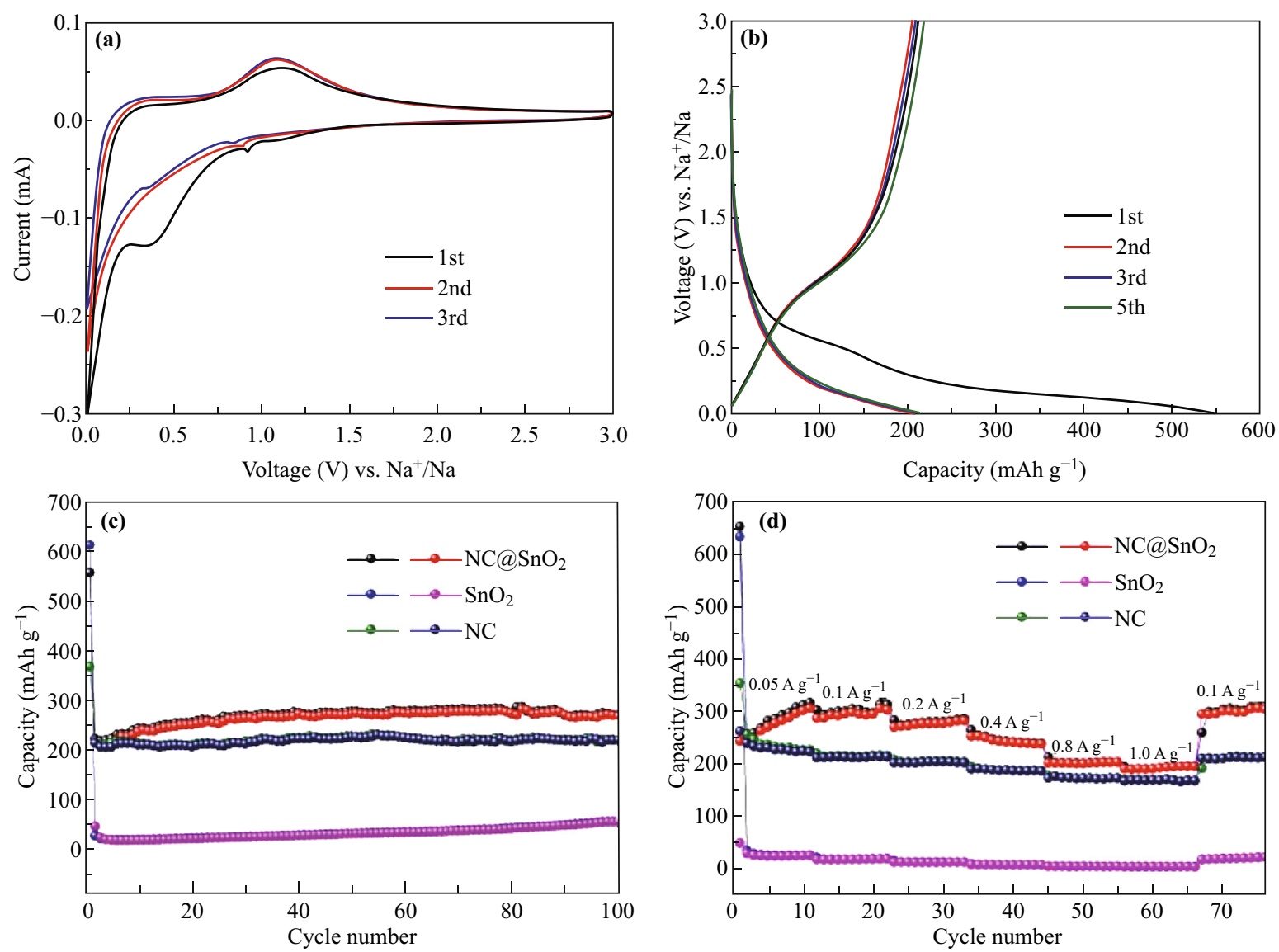

Fig. 6 Electrochemical performance for SIBs: a Cyclic voltammetry curves of $\mathrm{NC@SnO}$ at $0.1 \mathrm{mV} \mathrm{s}^{-1}$. b Charge-discharge voltage profiles of $\mathrm{NC} @ \mathrm{SnO}_{2}$. c Cycling performances of $\mathrm{NC} @ \mathrm{SnO}_{2}, \mathrm{SnO}_{2}$, and $\mathrm{NC}$ at $100 \mathrm{~mA} \mathrm{~g}{ }^{-1}$. d Rate capabilities of $\mathrm{NC}_{\mathrm{SnO}}, \mathrm{SnO}_{2}$, and $\mathrm{NC}$. (Color figure online)

$$
\begin{aligned}
& \mathrm{SnO}_{2}+4 \mathrm{Na}^{+}+4 \mathrm{e}^{-} \leftrightarrow \mathrm{Sn}+2 \mathrm{Na}_{2} \mathrm{O}, \\
& \mathrm{Sn}+\mathrm{xNa}^{+}+\mathrm{xe}^{-} \leftrightarrow \mathrm{Na}_{\mathrm{x}} \mathrm{Sn}(0<\mathrm{x}<4) .
\end{aligned}
$$

Figure $6 \mathrm{~b}$ displays the discharge/charge capacities of $555.7 / 212.5 \mathrm{mAh} \mathrm{g}^{-1}$ in the first charge/discharge cycle, respectively, with a coulombic efficiency of $38.2 \%$. The low coulombic efficiency can be attributed to the formation of SEI film, and the irreversible reaction of $\mathrm{SnO}_{2}$ with sodium ion to form $\mathrm{Na}_{\mathrm{x}} \mathrm{Sn}$ alloys in the first discharge process [46, 47]. In this work, the $\mathrm{SnO}_{2}$ and $\mathrm{NC}$ electrodes are used as a reference. In Fig. 6c, one can see that the discharge capacity of $\mathrm{NC} @ \mathrm{SnO}_{2}$ is about $270 \mathrm{mAh} \mathrm{g}^{-1}$, compared with 55 and $220 \mathrm{mAh} \mathrm{g}^{-1}$ of $\mathrm{SnO}_{2}$ and $\mathrm{NC}$ at $100 \mathrm{~mA} \mathrm{~g}^{-1}$ after 100 cycles. The rate performances for the three electrodes were also studied as shown in Fig. 6d. When the current densities were set at $0.05,0.1,0.2,0.4$, $0.8,1$, and $0.1 \mathrm{~A} \mathrm{~g}^{-1}$, the $\mathrm{NC} @ \mathrm{SnO}_{2}$ electrode exhibits the discharge capacities of about 295, 300, 280, 247, 202, 193, and $300 \mathrm{mAh} \mathrm{g}^{-1}$, respectively. These results are better than those of $\mathrm{SnO}_{2}$ and $\mathrm{NC}$ electrodes.

To further demonstrate the structural stability of hybrid $\mathrm{NC} @ \mathrm{SnO}_{2}$, the SEM images of electrodes after about 75 cycles are given in Figs. 7 and S6. The SEM images of $\mathrm{NC} @ \mathrm{SnO}_{2}$ and $\mathrm{SnO}_{2}$ electrodes as anode for LIBs after cycling are shown in Fig. 7. Compared to the SEM images of the $\mathrm{SnO}_{2}$ electrodes (Fig. 7c, d), we can observe the obvious NC could be retained, and the $\mathrm{SnO}_{2}$ nanoflowers are not completely collapsed as shown in Fig. 7a, b. It demonstrates that the hybrid $\mathrm{NC} @ \mathrm{SnO}_{2}$ electrodes have the better cycle performance and rate capability than those of $\mathrm{SnO}_{2}$ electrodes in the LIBs due to the more stable structure of hybrid $\mathrm{NC@} \mathrm{SnO}_{2}$ material. We also investigated the structural change of both $\mathrm{NC} @ \mathrm{SnO}_{2}$ and $\mathrm{SnO}_{2}$ electrodes for SIBs. As shown in the SEM images of NC@ $\mathrm{SnO}_{2}$ electrode after cycling (Fig. S6a), the network structure of the NC could still be observed and no obvious reunion in comparison with the $\mathrm{SnO}_{2}$ electrode (Fig. S6c). However, $\mathrm{SnO}_{2}$ nanoflowers are completely collapsed in both $\mathrm{NC} @ \mathrm{SnO}_{2}$ and $\mathrm{SnO}_{2}$ electrodes, as shown in the highmagnification SEM images (Fig. S6b, d). This is because that the formation of $\mathrm{Na}-\mathrm{Sn}$ alloy with enormous volume changes makes the pulverization of $\mathrm{SnO}_{2}$ material upon repetitive cycling [20]. These results indicated that $\mathrm{NC}$ nanofibers of the $\mathrm{NC} @ \mathrm{SnO}_{2}$ electrode can not only provide 


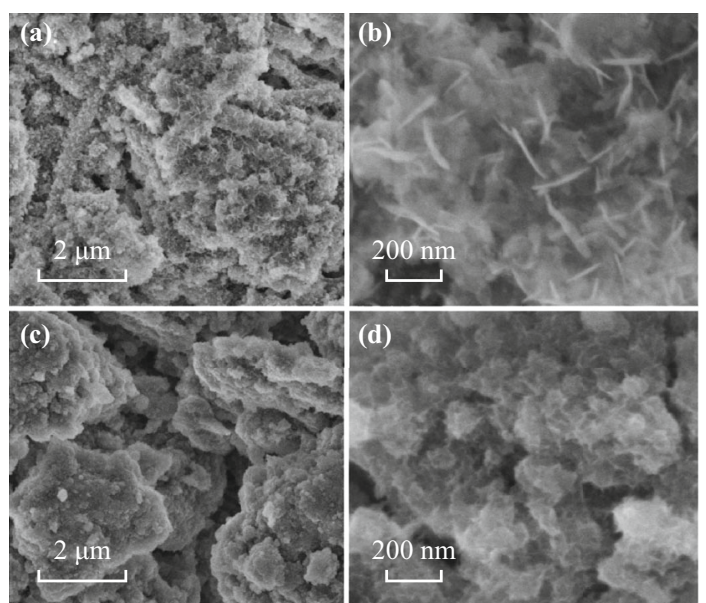

Fig. 7 SEM images of the electrodes after cycles for the Li-ion batteries: a, b $\mathrm{NC} @ \mathrm{SnO}_{2}$ and $\mathbf{c}, \mathbf{d ~} \mathrm{SnO}_{2}$

a conductive network, but also prevent the aggregation and pulverization of the $\mathrm{SnO}_{2}$ nanoflowers during the charge and discharge process.

\section{Conclusion}

In summary, we have successfully prepared a hybrid structure of $\mathrm{NC@} \mathrm{SnO}_{2}$ by electrospinning/hydrothermal methods. The NC nanofibers of the hybrid $\mathrm{NC} @ \mathrm{SnO}_{2}$ can prevent the agglomeration of $\mathrm{SnO}_{2}$ nanoflowers and effectively accelerate the transition of $\mathrm{Li}^{+} / \mathrm{Na}^{+}$ion to promote the rate capability. Moreover, the structure can make more surface of the nanoflower exposed and buffer the volume expansion of $\mathrm{SnO}_{2}$ to enhance discharge capacity and cycling performance during cycling process. In addition, the hybrid $\mathrm{NC} @ \mathrm{SnO}_{2}$ could deliver a discharge capacity of $750 \mathrm{mAh} \mathrm{g}^{-1}$ after 100 cycles at $1 \mathrm{~A} \mathrm{~g}^{-1}$ for Li-ion battery and $270 \mathrm{mAh} \mathrm{g}^{-1}$ after 100 cycles at $100 \mathrm{~mA} \mathrm{~g}^{-1}$ for Na-ion battery.

Acknowledgements This work was supported by the National Natural Science Foundation of China (Grant No. 51302079) and the National Natural Science Foundation of Hunan Province (Grant No. 2017JJ1008).

Open Access This article is distributed under the terms of the Creative Commons Attribution 4.0 International License (http://crea tivecommons.org/licenses/by/4.0/), which permits unrestricted use, distribution, and reproduction in any medium, provided you give appropriate credit to the original author(s) and the source, provide a link to the Creative Commons license, and indicate if changes were made.

\section{References}

1. J. Xu, J. Ma, Q. Fan, S. Guo, S. Dou, Recent progress in the design of advanced cathode materials and battery models for high-performance lithium- $\mathrm{X}(\mathrm{X}=\mathrm{O} 2, \mathrm{~S}, \mathrm{Se}, \mathrm{Te}, \mathrm{I} 2, \mathrm{Br} 2)$ batteries.
Adv. Mater. 29, 1606454 (2017). https://doi.org/10.1002/adma. 201606454

2. C. Cui, J. Xu, L. Wang, D. Guo, M. Mao, J. Ma, T. Wang, Growth of $\mathrm{NiCo}_{2} \mathrm{O}_{4} @ \mathrm{MnMoO}_{4}$ nanocolumn arrays with superior pseudocapacitor properties. ACS Appl. Mater. Interfaces 8(13), 8568-8575 (2016). https://doi.org/10.1021/acsami.6b02962

3. D. Guo, L. Lai, A. Cao, H. Liu, S. Dou, J. Ma, Nanoarrays: design, preparation and supercapacitor applications. RSC Adv. 5(69), 55856-55869 (2015). https://doi.org/10.1039/ C5RA09453D

4. F. Mao, W. Guo, J. Ma, Research progress on design strategies, synthesis and performance of $\mathrm{LiMn}_{2} \mathrm{O}_{4}$-based cathodes. RSC Adv. 5(127), 105248-105258 (2015). https://doi.org/10.1039/ C5RA21777F

5. J. Xu, Y. Dou, Z. Wei, J. Ma, Y. Deng, Y. Li, H. Liu, S. Dou, Recent progress in graphite intercalation compounds for rechargeable metal ( $\mathrm{Li}, \mathrm{Na}, \mathrm{K}, \mathrm{Al})$-ion batteries. Adv. Sci. 4(10), 1700146 (2017). https://doi.org/10.1002/advs.201700146

6. L. Wang, B. Ruan, J. Xu, H.K. Liu, J. Ma, Amorphous carbon layer contributing Li storage capacity to $\mathrm{Nb}_{2} \mathrm{O}_{5} @ \mathrm{C}$ nanosheets. RSC Adv. 5(45), 36104-36107 (2015). https://doi.org/10.1039/ C5RA05935F

7. Y. Cai, J. Ma, T. Wang, Hydrothermal synthesis of $\alpha-\mathrm{Ni}(\mathrm{OH})_{2}$ and its conversion to $\mathrm{NiO}$ with electrochemical properties. J. Alloys Compd. 582, 328-333 (2014). https://doi.org/10.1016/j.jall com.2013.07.206

8. C. Cui, X. Li, Z. Hu, J. Xu, H. Liu, J. Ma, Growth of $\mathrm{MoS}_{2} @ \mathrm{C}$ nanobowls as a lithium-ion battery anode material. RSC Adv. 5(112), 92506-92514 (2015). https://doi.org/10.1039/ C5RA17992K

9. V. Etacheri, R. Marom, R. Elazari, G. Salitra, D. Aurbach, Challenges in the development of advanced Li-ion batteries: a review. Energy Environ. Sci. 4(9), 3243-3262 (2011). https://doi. org/10.1039/c1ee01598b

10. P. Roy, S.K. Srivastava, Nanostructured anode materials for lithium ion batteries. J. Mater. Chem. A 3(6), 2454-2484 (2015). https://doi.org/10.1039/C4TA04980B

11. L. Wang, Y.-G. Sun, L.-L. Hu, J.-Y. Piao, J. Guo, A. Manthiram, J. Ma, A.-M. Cao, Copper-substituted $\mathrm{Na}_{0.67} \mathrm{Ni}_{0.3-\mathrm{x}} \mathrm{Cu}_{\mathrm{x}} \mathrm{Mn}_{0.7} \mathrm{O}_{2}$ cathode materials for sodium-ion batteries with suppressed $\mathrm{P}_{2}-\mathrm{O}_{2}$ phase transition. J. Mater. Chem. A 5(18), 8752-8761 (2017). https://doi.org/10.1039/C7TA00880E

12. V. Palomares, P. Serras, I. Villaluenga, K.B. Hueso, J. CarreteroGonzalez, T. Rojo, Na-ion batteries, recent advances and present challenges to become low cost energy storage systems. Energy Environ. Sci. 5(3), 5884-5901 (2012). https://doi.org/10.1039/ c2ee02781j

13. Y. Chen, J. Ma, Q. Li, T. Wang, Gram-scale synthesis of ultrasmall $\mathrm{SnO}_{2}$ nanocrystals with an excellent electrochemical performance. Nanoscale 5(8), 3262-3265 (2013). https://doi.org/10. 1039/c3nr00356f

14. S.J.R. Prabakar, Y.-H. Hwang, E.-G. Bae, S. Shim, D. Kim, M.S. Lah, K.-S. Sohn, M. Pyo, $\mathrm{SnO}_{2}$ /graphene composites with selfassembled alternating oxide and amine layers for high Li-storage and excellent stability. Adv. Mater. 25(24), 3307-3312 (2013). https://doi.org/10.1002/adma.201301264

15. J. Deng, Y. Chen, J. Ma, E. Zhang, T. Wang, Solvothermal synthesis of hollow urchin-like $\mathrm{SnO}_{2}$ nanospheres with superior lithium storage behavior. J. Nanosci. Nanotechnol. 13(6), 4297-4301 (2013). https://doi.org/10.1166/jnn.2013.7181

16. F. Yan, X. Tang, Y. Wei, L. Chen, G. Cao, M. Zhang, T. Wang, Stannous ions reducing graphene oxide at room temperature to produce $\mathrm{SnO}_{\mathrm{x}}$-porous, carbon-nanofiber flexible mats as binderfree anodes for lithium-ion batteries. J. Mater. Chem. A 3(24), 12672-12679 (2015). https://doi.org/10.1039/C5TA02107C 
17. Y. Zhao, C. Wei, S. Sun, L.P. Wang, Z.J. Xu, Reserving interior void space for volume change accommodation: an example of cable-like mwnts@ $\mathrm{SnO}_{2} @ \mathrm{C}$ composite for superior lithium and sodium storage. Adv. Sci. 2(6), 1500097 (2015). https://doi.org/ 10.1002/advs.201500097

18. C. Guan, X. Wang, Q. Zhang, Z. Fan, H. Zhang, H.J. Fan, Highly stable and reversible lithium storage in $\mathrm{SnO}_{2}$ nanowires surface coated with a uniform hollow shell by atomic layer deposition. Nano Lett. 14(8), 4852-4858 (2014). https://doi.org/10.1021/ nl502192p

19. X.M. Yin, C.C. Li, M. Zhang, Q.Y. Hao, S. Liu, L.B. Chen, T.H. Wang, One-step synthesis of hierarchical $\mathrm{SnO}_{2}$ hollow nanostructures via self-assembly for high power lithium ion batteries. J. Phys. Chem. C 114(17), 8084-8088 (2010). https://doi.org/10. 1021/jp100224x

20. L. Chen, X. Yin, L. Mei, C. Li, D. Lei et al., Mesoporous $\mathrm{SnO}_{2} @$ carbon core-shell nanostructures with superior electrochemical performance for lithium ion batteries. Nanotechnology 23(3), 035402 (2011). https://doi.org/10.1088/0957-4484/23/3/ 035402

21. L. Fan, X. Li, B. Yan, J. Feng, D. Xiong et al., Controlled $\mathrm{SnO}_{2}$ crystallinity effectively dominating sodium storage performance. Adv. Energy Mater. 6(10), 1502057 (2016). https://doi.org/10. 1002/aenm.201502057

22. M. Dirican, Y. Lu, Y. Ge, O. Yildiz, X. Zhang, Carbon-confined $\mathrm{SnO}_{2}$-electrodeposited porous carbon nanofiber composite as high-capacity sodium-ion battery anode material. ACS Appl. Mater. Interfaces. 7(33), 18387-18396 (2015). https://doi.org/10. 1021/acsami.5b04338

23. B. Huang, X. Li, Y. Pei, S. Li, X. Cao, R.C. Massé, G. Cao, Novel carbon-encapsulated porous $\mathrm{SnO}_{2}$ anode for lithium-ion batteries with much improved cyclic stability. Small 12(14), 1945-1955 (2016). https://doi.org/10.1002/smll.201503419

24. J. Xu, G. Jia, W. Mai, H.J. Fan, Energy storage performance enhancement by surface engineering of electrode materials. Adv. Mater. Interfaces 3(20), 1600430 (2016). https://doi.org/10.1002/ admi. 201600430

25. X. Zhou, L.J. Wan, Y.G. Guo, Binding $\mathrm{SnO}_{2}$ nanocrystals in nitrogen-doped graphene sheets as anode materials for lithiumion batteries. Adv. Mater. 25(15), 2152-2157 (2013). https://doi. org/10.1002/adma.201300071

26. X. Wang, X. Cao, L. Bourgeois, H. Guan, S. Chen et al., N-doped graphene- $\mathrm{SnO}_{2}$ sandwich paper for high-performance lithium-ion batteries. Adv. Funct. Mater. 22(13), 2682-2690 (2012). https:// doi.org/10.1002/adfm.201103110

27. Y. Liu, C. Zhang, L. Shao, Z. Tian, Z. Deng, C. Gao, A mini review on nanocarbon-based $1 \mathrm{D}$ macroscopic fibers: assembly strategies and mechanical properties. Nano-Micro Lett. 9, 51 (2017). https://doi.org/10.1007/s40820-017-0151-7

28. Y. Liu, Y. Jiao, Z. Zhang, F. Qu, A. Umar, X. Wu, Hierarchical $\mathrm{SnO}_{2}$ nanostructures made of intermingled ultrathin nanosheets for environmental remediation, smart gas sensor, and supercapacitor applications. ACS Appl. Mater. Interfaces 6(3), 2174-2184 (2014). https://doi.org/10.1021/am405301v

29. Z. Lin, X. Xiong, J. Zheng, G. Wang, C. Yang, Three-dimensional $\mathrm{N}$-doped graphene as anode material with superior cycle stability for sodium ion batteries. Mater. Lett. 202, 123-126 (2017). https://doi.org/10.1016/j.matlet.2017.05.046

30. Y. Luo, X. Zhou, Y. Zhong, M. Yang, J. Wei, Z. Zhou, Preparation of core-shell porous magnetite@carbon nanospheres through chemical vapor deposition as anode materials for lithium-ion batteries. Electrochim. Acta 154, 136-141 (2015). https://doi.org/10.1016/j.electacta.2014.12.038

31. H. Wang, S. Dou, S. Wang, L. Wang, T. Wang, J. Ma, J. Zhang, $\mathrm{Y}$. Yu, Synthesis of electrocatalytically functional carbon honeycombs through cooking with molecule precursors. Int.
J. Hydrogen Energy 42(10), 6472-6481 (2017). https://doi.org/ 10.1016/j.ijhydene.2017.01.187

32. D. Zhou, X. Li, L.-Z. Fan, Y. Deng, Three-dimensional porous graphene-encapsulated CNT@ $\mathrm{SnO}_{2}$ composite for high-performance lithium and sodium storage. Electrochim. Acta 230, 212-221 (2017). https://doi.org/10.1016/j.electacta.2017.02.016

33. Y. Yan, F. Du, X. Shen, Z. Ji, X. Sheng, H. Zhou, G. Zhu, Largescale facile synthesis of $\mathrm{Fe}$-doped $\mathrm{SnO}_{2}$ porous hierarchical nanostructures and their enhanced lithium storage properties. J. Mater. Chem. A 2(38), 15875-15882 (2014). https://doi.org/10. 1039/C4TA02077D

34. X. Hou, Y. Hu, H. Jiang, Y. Li, W. Li, C. Li, One-step synthesis of $\mathrm{SnO}_{\mathrm{x}}$ nanocrystalline aggregates encapsulated by amorphous $\mathrm{TiO}_{2}$ as an anode in Li-ion battery. J. Mater. Chem. A 3(18), 9982-9988 (2015). https://doi.org/10.1039/C5TA01106J

35. J. Liu, Q. Zhang, J. Yang, H. Ma, M.O. Tade, S. Wang, J. Liu, Facile synthesis of carbon-doped mesoporous anatase $\mathrm{TiO}_{2}$ for the enhanced visible-light driven photocatalysis. Chem. Commun. 50(90), 13971-13974 (2014). https://doi.org/10.1039/ $\mathrm{C} 4 \mathrm{CC} 05544 \mathrm{~F}$

36. B. He, W.-C. Li, A.-H. Lu, High nitrogen-content carbon nanosheets formed using the schiff-base reaction in a molten salt medium as efficient anode materials for lithium-ion batteries. J. Mater. Chem. A 3(2), 579-585 (2015). https://doi.org/10.1039/ C4TA05056H

37. J. Ou, Y. Zhang, L. Chen, Q. Zhao, Y. Meng, Y. Guo, D. Xiao, Nitrogen-rich porous carbon derived from biomass as a high performance anode material for lithium ion batteries. J. Mater. Chem. A 3(12), 6534-6541 (2015). https://doi.org/10.1039/ C4TA06614F

38. W. Lei, L. Han, C. Xuan, R. Lin, H. Liu, H.L. Xin, D. Wang, Nitrogen-doped carbon nanofibers derived from polypyrrole coated bacterial cellulose as high-performance electrode materials for supercapacitors and Li-ion batteries. Electrochim. Acta 210, 130-137 (2016). https://doi.org/10.1016/j.electacta.2016.05. 158

39. C. Zhu, X. Xia, J. Liu, Z. Fan, D. Chao, H. Zhang, H.J. Fan, $\mathrm{TiO}_{2}$ nanotube@ $\mathrm{SnO}_{2}$ nanoflake core-branch arrays for lithium-ion battery anode. Nano Energy 4, 105-112 (2014). https://doi.org/ 10.1016/j.nanoen.2013.12.018

40. B. Jiang, Y. He, B. Li, S. Zhao, S. Wang, Y.B. He, Z. Lin, Polymer-templated formation of polydopamine-coated $\mathrm{SnO}_{2}$ nanocrystals: anodes for cyclable lithium-ion batteries. Angew. Chem. Int. Ed. 56(7), 1869-1872 (2017). https://doi.org/10.1002/ anie. 201611160

41. M. Zhang, Z. Sun, T. Zhang, D. Sui, Y. Ma, Y. Chen, Excellent cycling stability with high $\mathrm{SnO}_{2}$ loading on a three-dimensional graphene network for lithium ion batteries. Carbon 102, 32-38 (2016). https://doi.org/10.1016/j.carbon.2016.02.032

42. R. Li, B. Wang, S. Ji, P. Jin, Facile synthesis of ultrasmall stannic oxide nanoparticles as anode materials with superior cyclability and rate capability for lithium-ion batteries. RSC Adv. 6(59), 54179-54184 (2016). https://doi.org/10.1039/C6RA00964F

43. R. Hu, Y. Ouyang, T. Liang, H. Wang, J. Liu, J. Chen, C. Yang, L. Yang, M. Zhu, Stabilizing the nanostructure of $\mathrm{SnO}_{2}$ anodes by transition metals: a route to achieve high initial coulombic efficiency and stable capacities for lithium storage. Adv. Mater. 29(13), 1605006 (2017). https://doi.org/10.1002/adma. 201605006

44. W. Chen, K. Song, L. Mi, X. Feng, J. Zhang, S. Cui, C. Liu, Synergistic effect induced ultrafine $\mathrm{SnO}_{2}$ /graphene nanocomposite as an advanced lithium/sodium-ion batteries anode. J. Mater. Chem. A 5(20), 10027-10038 (2017). https://doi.org/10. 1039/C7TA01634D

45. M. Yang, X. Li, B. Yan, L. Fan, Z. Yu, D. Li, Reduced graphene oxide decorated porous $\mathrm{SnO}_{2}$ nanotubes with enhanced sodium 
storage. J. Alloys Compd. 710, 323-330 (2017). https://doi.org/ 10.1016/j.jallcom.2017.03.255

46. R.S. Kalubarme, J.-Y. Lee, C.-J. Park, Carbon encapsulated tin oxide nanocomposites: an efficient anode for high performance sodium-ion batteries. ACS Appl. Mater. Interfaces. 7(31), 17226-17237 (2015). https://doi.org/10.1021/acsami.5b04178
47. S. Li, Y. Wang, J. Qiu, M. Ling, H. Wang, W. Martens, S. Zhang, $\mathrm{SnO}_{2}$ decorated graphene nanocomposite anode materials prepared via an up-scalable wet-mechanochemical process for sodium ion batteries. RSC Adv. 4(91), 50148-50152 (2014). https://doi.org/10.1039/C4RA09699A 